\title{
A Notion at Risk: Interrogating the Educational Role of Off-Campus Study in the Liberal Arts
}

\author{
Andrew Law \\ Denison University
}

\section{Sus a M M n icke \\ Soutbwestern University}

You always got to be prepared but you never know for what.

Bob Dylan ${ }^{1}$

The American tradition of liberal arts education assumes that choosing to become an educated person means choosing to become a responsible person-a person capable of engaging in thoughtful reflection and, in turn, acting with empathy and compassion and making informed moral/ethical judgments and choices. In other words, neither education nor knowledge is value free, and therefore the educational connection between thought and action must be an intentional one. It is our argument that we need to take on the challenge of applying these pedagogical assumptions to off-campus study.

This isn't about particular off-campus study programs, per se, but about how we at liberal arts colleges make manifest, through on-campus advising and administrative practices and policy, the educational role of off-campus study. Our conviction is that we should act as educators ${ }^{2}$ to challenge students to develop as individuals who can understand their own limitations, their own particular socio-political, economic, historical and cultural embeddedness, and who have tools of critical reflection with which to make the moral/ethical judgments and choices that are the imperatives of a liberal arts education.

\section{A Iittle knowledge is a dangerous thing ...}

Mission statements for off-campus study units usually ascribe only the most generalized educational value to the experience, more often than not failing to suggest any purposeful relationship between those experiences and the pedagogical goals that inform the broader educational project at liberal arts 
institutions. These statements tend instead to highlight the benefits of offcampus study solely in terms of the "new perspectives" it supposedly adds to the student's experience of the curriculum. The underlying ideological assumption holds two premises: first, that the movement of students to and from the United States helps to bridge cultural differences and second, that it inspires global perspectives and competencies among students.

While it is hard to disagree with the first assertion, the second is profoundly troubling. The drumbeat of propaganda regarding the need to move Americans abroad in order to instill the competencies necessary for success in a global marketplace has had the effect (much as the $A$ Nation at Risk report had on primary and secondary education) of precipitating a complex set of issues down to a simple formula. Education abroad professionals too often assume that mastery of cultural knowledge and an appreciation of difference will serve to make a measurable difference in how American college students view the world and take their place in it (and, ostensibly, help guarantee the long-term economic success of the United States).

In contrast, the liberal arts tradition argues that the transformation of the individual lies in the pursuit of, considered engagement, and, in turn, action with a newly informed moral and ethical imperative. This certainly includes the aims that Karen Jenkins, former president of Brethren Colleges Abroad, ascribed to teaching for "global competence:"

...to equip each student, regardless of whether he or she has studied abroad, with an ability to grasp concepts that shape our world; to view issues and solutions from the perspective of a person with a different culture, language, and history; and to see how each citizen's choices affect others around the corner and across the globe. ${ }^{3}$

However, a liberal arts framework is not premised solely on the accumulation of information. It demands that students also question the efficacy of such knowledge, even if gained through first-hand experience. As Nadinne Cruz, former director of the Haas Center for Public Service at Stanford University, wrote over fifteen years ago:

Even carefully crafted guidelines for [the practice of experiential learning] can do damage if they are not placed in the context of social realities, namely different and competing interests as well as outright conflict, based on, for example, class, race, gender, and even 
nationality. We simply cannot gloss over, without cost to us, concrete conflict situations and experiences that make difficult the application of concepts such as [experiential learning]. ${ }^{4}$

Addressing his first convocation as President of Lawrence University, Richard Warch offered a vision of the liberal arts that sought both to validate the goal of assisting students in their intellectual development and, more importantly, to delineate the moral and ethical context within which that intellectual activity ultimately finds its meaning and purpose.

[Lawrence] university takes as its motto the dying words of Goethe, "Light, Light, More Light!”...an appropriate claim for a college devoted to liberal learning in the arts and sciences.

[Miguel] Unamuno begs to differ. In the concluding pages of the Spanish philosopher's work Tragic Sense of Life, he wrote: "Light, light, more light! they tell the dying Goethe cried. No, warmth, warmth, more warmth, for we die of cold and not of darkness. It is not the night kills, but the frost." ${ }^{5}$

In the context of the cultural malaise of the late seventies, Warch's point was to admonish his colleagues and the students by reminding them that breadth and depth of knowledge are necessary but not sufficient to becoming a liberally educated person. This educational project is realized only when students grasp the intentional relationship that must exist between thinking and acting.

Action without purpose is merely activity. To devote ourselves simply and solely to receiving light, without the accompanying intention to radiate warmth is to sterilize the mission and to deny the tradition of the university. ${ }^{6}$

It is our argument that we find ourselves in a similar moment with regard to off-campus study in the context of liberal arts institutions. We believe that the educational goals associated with off-campus study are too often concerned solely with "receiving light" (i.e. consuming knowledge), wherein it is supposed that the mere exposure of students to difference somehow imbues them with the kind of cultural capital appropriate for a liberally educated individual and necessary for success in a global marketplace. 
Witness, for example, the NAFSA webinar entitled "The Role of International Education in Global Workforce Development" which offered participants the opportunity to "gain a better understanding of what constitutes a 'globalready' graduate and how institutions can better prepare their students to address the many critical issues challenging our global future." 7 This view of off-campus study is pervasive, informing how most colleges and universities promote the role of off-campus study in their degree programs by trumpeting its ability to provide students with the intercultural competence mandated by globalization.

What exactly is wrong with this picture? Is it not the case that our students, by virtue of their off-campus study experience, are better prepared for the global marketplace? Maybe, maybe not, but our point is that framing the rationale for off-campus study solely in these terms misses the point of the experience as an educational vehicle for the liberal arts. If we assume instead that the capacity for critical thought and moral/ethical action is the primary educational end, it is apparent that the growth in students' analytical capacity associated with the global workforce development model is limited by its pragmatic utility - focusing exclusively on the ability to acknowledge and respond to difference in specific contexts.

This construction turns on an oversimplified understanding of difference. We in the education abroad field are often so enamored of the explanatory power of culture that we ignore the inherent conflicts and complexity associated with difference in favor of an assumption that mere exposure to culture teaches about difference. ${ }^{8}$ A liberal arts framework posits that we should be equally concerned both with the recognition of difference, which exposure can impart, and with the ability to interrogate and negotiate the complex array of socio-political, economic, historical and cultural issues that inform that difference. The educational goal is for students to develop an interrogative habit of mind (reflexivity), one that tackles the continuing challenge of communicating across difference, rather than merely a capacity for reflection on demand.

The question of how to impart reflexivity among our students is by its very nature a pedagogical one, and it is our argument that we as educators need to restructure our campus-based practice accordingly.

\section{What's pedagogy got to do, got to do with it?}

The tendency to mistake the accrual of knowledge for the development of reflexivity has led to the ideological reification ${ }^{9}$ of the off-campus advising process, engendering a professional environment in which off-campus study advisors too often see themselves as facilitators rather than as educators. This 
has, in turn, led to presenting the advising process to students as one involving administrative logistics (which we believe includes curricular concerns) rather than pedagogical concerns.

By choosing to ground our practice in the foundational questions that inform the liberal arts tradition - '"why,' 'for what purpose,' and 'toward what social good' do we do what we do" 10 — we set the stage for an approach to off-campus study that is rooted in the broader educational mission of the liberal arts and thereby pedagogical in nature, as opposed to administratively driven and thereby procedural in nature. Our work should send the message that off-campus study is a "liberal arts laboratory" through which students confront the complex challenges of engaging difference, the need for reflexivity in response to those challenges, and, ultimately, their agency in that process. Our charge as educators is to assist students in comprehending that not knowing, that recognizing the world does not revolve around oneself, is critical to becoming an effective person in the world-a person who is conscious of the limitations and possibilities of her/his agency in the world. In so doing we transform the off-campus study process from one based on the premise of mastery to one concerned with "the connectedness among our learning, our doing, and our being." 11

Adopting a pedagogical frame for our work with students necessitates a shift from encouraging mastery of a set of cultural knowledges/histories (as Jenkins describes) to a position where we seek to engage students in the practice of intellectual reflexivity. In helping students to see the inherent limitations of any one person's knowledge or perceptions we are also assisting them in recognizing the importance of conflict and vulnerability in deepening one's self-understanding. In the end, it is primarily through the self-effacing acknowledgement of the profound limitations on our ability to know anything that we begin to see the necessary relationship between reflexive critical thinking (theory) and acting with moral/ethical intentionality (informed praxis).

However, it is our belief that the profound possibilities for negotiating ambiguity that are present in the process of off-campus study are precisely what we fail to communicate in our work as educators. We instead offer our students the possibility of knowing other peoples and societies, which when combined with the too rarely discussed issue that study abroad students are a privileged subset of an already privileged group — those that are able to pursue higher education - serves at best to exacerbate a counterproductive vision of the nature of liberal learning and at worst to instill a neo-colonialist arrogance among our students wherein they presume the right to know. 
What is most compelling about bringing the liberal arts lens to bear on off-campus study advising is the possibility of developing a framework that strives to facilitate engagement with complexity instead of one that presumes that off-campus study bestows upon students the capacity to know the world and/or to fathom precisely what informs another's actions. In other words, we are advocating for a pedagogical approach to off-campus study that foregrounds the importance of learning to engage with and respond to questions rather than seeking certitude. As John J. Degioia, President of Georgetown University, argued in his inaugural address:

The questions central to us carry powerful tensions and elude fixed, final, definitive answers. Our work is messy. Our business lies in disorder and conflict... when we deny these tensions we deny our reality...paradoxical as this may sound, we are most authentic when these tensions are most alive. ${ }^{12}$

It is important to acknowledge here that calling attention to the problematic nature of the learning that takes place on off-campus study programs does not mean that we are advocating that students adopt a particular ideological position or political stance.

As students grapple with issues and gain insights into the lives of those who too often remain voiceless, they inevitably will develop their own perspectives and politics. Our job is to provide advising and programming that will assist and inspire them to combine concern and compassion with critical thinking and analysis. ${ }^{13}$

The point is to acknowledge the complex relationship that exists between analyzing and acting, and our role in shaping students' confrontations with that challenge.

\section{Do the right thing}

Early on in Spike Lee's Do the Right Thing, Da' Mayor pulls Mookie aside to offer him words of wisdom ${ }^{14}$. The importance of this gesture, and why the movie derives its title from these words, is that Da' Mayor is exhorting Mookie to consider his choices within the context of the broader community, rather than merely in the context of his own needs and/or desires. The point is not only that one needs to think through the rightness of the actions one takes, 
but also that one must often analyze and act in the face of profound ambiguity and disagreement. What Da' Mayor is imparting to Mookie is his wisdom about the way life works. Mookie will not always know exactly what the "right thing" is, so the point is to strive for thoughtful engagement — doing the right thing — rather than only seeking certitude.

After his brief interaction with Da' Mayor, Mookie sets forth on a day-long voyage of experiential learning that ultimately results in his decision to throw the garbage can through the window of Sal's Pizzeria, thereby inciting a riot. What infuriated people about Spike Lee's resolution was that Mookie resorted to violence, but this draws us away from Lee's salient point regarding the importance of informed engagement - the necessity of analyzing and doing. ${ }^{15}$

If we were advising about this experience, how would we prepare Mookie? In our mind, Da' Mayor plays the role of educator - he provides Mookie with an educational framework grounded in the reality of moral and ethical challenges, but not a promise of certitude. Likewise, we must not present offcampus study as a connect-the-dots experience (a "magical elixir" of cultural learning), but instead call into question the assumptions that students often bring to their off-campus experience. (And this does not mean just cultural or pre-professional assumptions, but the broad range of assumptions about the nature of difference associated with coming from a privileged setting in a privileged country.) Our educational responsibility is to undermine the presumption of knowing and to model in our practice an intellectual framework for moral and ethical engagement in the face of ambiguity.

This process will obviously lead students in varying directions, and we may not always like the results. We frankly don't know whether Da' Mayor approved of Mookie's particular choice. While the two of us would love our work to engender among all students a sincere concern for issues of social and economic justice, in the end this is neither possible nor is it our sole job as educators. It would be the height of foolishness to think that all advising interactions are going to produce profound results, that a single program model will prove educationally transformative for all students, or that all students will be equally engaged with the challenge of engaging with difference. Our job is to assume the role of the pedagogue by confronting students with a terrain of appropriate, open-ended challenges, setting the stage as best we can for their potentially transformative intellectual and personal engagement with those challenges, and then repeating this cycle as seems appropriate and constructive.

A critical step in embracing this approach to off-campus study is recognizing that one's charge is institutional in nature. Much as Da' Mayor was the 
tender of his community, a person whose daily interactions with his neighbors were directed toward realizing constructive social relations on his block, it is critical for us to recognize that our principle responsibility is to the broader educational mission of the liberal arts - to assist students in their development as thoughtful, responsible, and socially-engaged individuals.

In essence, off-campus study provides a laboratory setting for the liberal arts. A liberal arts education provides students with intellectual tools, and our job as off-campus study educators is to assist students in learning to apply those tools. International awareness and intercultural competence are often cited as the primary goals for off-campus study. However, it is our belief that these are in fact simply a means to the end of the broader goals of the liberal arts. Our job as off-campus study educators is not merely to instill sensitivities. It is instead to create fertile ground for students to cultivate an analytical and increasingly complex understanding of social, economic, and political relationships in the world and their responsibility in those relationships.

\section{So now what?}

In the week that we were finishing writing this essay, the front page of The New York Times carried a photo of a grieving man clutching a dead body in the wake of an Islamic Jihad suicide bombing in Tel Aviv ("Suicide Bombing in Israel Kills 9; Hamas Approves”) and articles describing: the continuing catastrophe of Katrina ("In Attics and Rubble, More Bodies and Questions"), immigrant rallies for civil rights ("Immigrants Rally in Scores of Cities for Legal Status") and the conservative backlash against those demonstrations ("Demonstrations on Immigration Harden a Divide"), and the failing Middle East policies of the Bush Administration ("Arab Democracy, a U.S. Goal, Falters"). ${ }^{16}$

In the face of such widespread inhumanity, tragedy, and blithe incompetence, it strikes us that the intercultural competencies that we claim to offer through off-campus study are too often merely palliatives for the privileged. The stakes of the widespread environmental, social, and economic challenges that the global and U.S. communities now face and the risks associated with how we educate our students to engage those stakes are enormous. Thus we cannot allow the discourse that informs our practice to rest easily in its self-congratulatory assumptions of increasing the intercultural and/or global awareness and sensitivity of this generation of college-educated Americans. As Colonel H.R. McMaster, who has a doctorate in history, offered when describing the Army's experience in the first years of the Iraq War and his regiment's recent efforts to address the social, political, and recent military turmoil in Tal Afar, Iraq: 
When we first got here, we made a lot of mistakes. We were like a blind man, trying to do the right thing but breaking a lot of things.... It is so damn complex. If you ever think you have the solution to this, you're wrong, and you're dangerous. You have to keep listening and thinking and being critical and self-critical. ${ }^{17}$

Such analytical capacities and personal engagement must be engendered not only among our students, but also among ourselves as educators in the field. We have for too long failed in our practice to address the complex and messy sociopolitical and economic discourses that inform the world in which we work, which has in turn allowed our students to go forth with the naïve assumption that the world is a benign place whose only complexity stems from cultural miscommunication or the like. We must recognize that there are very real dangers inherent in the intercultural communication and personal development discourses used by off-campus study professionals and cease casually consuming and reproducing for our students those facile promises of fulfillment.

This essay has grown out of work we have done, principally though colloquia, to engender a critical conversation concerning educational practice in the field of off-campus study, particularly among administrators and advisors at liberal arts colleges and universities. It is our sincere hope that by sharing the discourse of critique we've developed over the last half decade that we can focus the energy of our many valued colleagues on two fundamental issues: 1) how the processes of constructing knowledge and power frame local and global discourses and, in turn, the terrain of our field, and 2) the crucial role that pedagogical imperatives must play in shaping our efforts to engage students with those processes. Thus we choose to end our essay with no answers at hand, but only the possibility for more questions, debate, and continuing revision of educational practice. But then, that's the point.

\section{A cknow l edge me nts}

This essay is the product of numerous conversations and musings in a variety of settings and we could not have produced it without some key assistance along the way. Initially the Global Partners consortium (a Mellon Foundation-funded project which included members of the Associated Colleges of the Midwest, the Associated Colleges of the South, and the Great Lakes Colleges Association) generously funded several retreats during which we gathered with an eclectic and lively set of colleagues to sketch out the philosophical foundation and intellectual terrain on which the rest of our work would unfold. 
The ideas contained in this piece were further formed and tested through two workshops, one funded by the Global Partners and the other by Arcadia University's Center for Education Abroad. We are indebted to the funders as well as the engaged and insightful workshop participants who brought thoughtful critical analysis to bear. In particular, we owe a word of thanks to Patti Brown and Lorna Stern, each of whom took special care in offering suggestions and support along the way, helping to create an ultimately much improved work. Lastly, we thank the students with whom we interact every day on our home campuses. They often rise to the challenge we present in the essay (in occasionally unexpected ways), making the effort of writing the piece and practicing its basic tenets well worth the effort.

\section{Notes}

${ }^{1}$ Bob Dylan, "Sugar Baby," Love and Theft, Columbia CK85975

${ }^{2}$ We have intentionally chosen to employ the term educator, as opposed to advisor or administrator, because we wish to underscore the pedagogical role we sh ould play in our work in off-campus study units.

${ }^{3}$ Karen Jenkins, "International Education in an Altered World," Priorities (Summer 2002): 4.

${ }^{4}$ Nadinne Cruz, "A Challenge to the Notion of Service," Experiential Education (November/December 1989): 322.

5 Richard Warch, "Unamuno Begs to Differ," address to Lawrence University matriculation convocation, Sept. 27, 1979: 3-4.

${ }^{6}$ Ibid, 4.

7 NAFSA email of December 5, 2005 to the Education Abroad network

8 See Chip Peterson, "Class and Study Abroad: Combining concern and compassion in critical analysis," Transitions Abroad, (July/August 1997): 77.

${ }^{9}$ Here we take reification to denote the idea that a concept has become accepted as "common sense," no longer calling attention to the fact that it is constructed knowledge.

10 Richard Warch, "Unamuno Begs to Differ," 5.

${ }^{11}$ Chip Peterson, "Class and Study Abroad," 79.

12 John J. Degioia, "Engaging the Tensions, Living the Questions: An excerpt from President John J. Degioia's inaugural address, DAR Constitution Hall, Oct. 13, 2001," Georgetown Magazine (Winter 2002): 23.

13 Chip Peterson, "Class and Study Abroad," 79.

${ }^{14}$ Do the Right Thing, Spike Lee, 1989. 
15 John Bullard, President, Sea Education Association, often shares with new Woods Hole SEA Semester students the following insight as a navigational point of reference for the journey they are starting: "If you act without thinking, you are dangerous. If you think without doing, you are irrelevant." The point being, obviously, that the pedagogical goal of the analytical and experiential learning students are pursuing on the SEA Semester is to engender a necessary and real connection between thought and action.

16 Greg Myre and Dina Kraft, "Suicide Bombing in Israel Kills 9; Hamas Approves," The New York Times (18 April 2006): A1. Shaila Dewan, "In Attics and Rubble. More Bodies and Questions," The New York Times (11 April, 2006): A1. Rachel L. Swarns, "Immigrants Rally in Scores of Cities for Legal Status," The New York Times (11 April, 2006): A1. David D. Kirkpatrick, "Demonstrations on Immigration harden a Divide," The New York Times (17 April, 2006): A1. Hassan M. Fattah, “Arab Democracy, a U.S. Goal, Falter," The New York Times (10 April 2006): A1.

17 George Packer, "The Lesson of Tal Afar: Is it too late for the administration to correct its course in Iraq?," The New Yorker (April 10, 2006): 50, 57. 
